\title{
Comparative Analysis of Characterization Methods of Potential Environmental Pollution Risk from Livestock and Poultry Breeding
}

\author{
Bojie Yan ${ }^{1 *}$, Jingjie Yan $^{2}$ \\ ${ }^{1}$ Ocean College of Minjiang University, Fuzhou, China \\ ${ }^{2}$ College of Telecommunications and Information Engineering, Nanjing \\ University of Posts and Telecommunications, Nanjing, China
}

Received: 22 April 2018

Accepted: 7 May 2018

\begin{abstract}
Based on statistics data of livestock and poultry of Guangdong Province, seven characterization methods were used to characterize potential environmental pollution risk of livestock and poultry breeding (LPB) of Guangdong and were analyzed comparatively. The results showed that the results of different characterization methods of potential environmental pollution risk of LPB were generally uneven in spatial distribution. The maximum value of seven characterization methods of potential environmental pollution risk of LPB were all in Shunde District, but the minimum value of seven characterization methods of potential environmental pollution risk of LPB were in different counties. In addition, the number of counties exceeding the safety thresholds also had large differences among different characterization methods of potential environmental pollution risk of LPB. The maximum number, second number, and minimum number of counties exceeding safety thresholds was by the alarm value of pig manure equivalent load of farmland calculated by nitrogen (AVPMELFN), livestock density (LD), and the pig manure equivalent load of farmland calculated by phosphorus (PMELFP), which accounting for $82.22 \%, 53.89 \%$, and $11.11 \%$ of total counties, respectively. It showed that the most stringent method was the AVPMELFN followed by the LD, and the least stringent method was the PMELFP.
\end{abstract}

Keywords: livestock and poultry, potential, environmental pollution, characterization methods, comparative analysis

\section{Introduction}

With the rapid development of China's national economy, LPB has been expanding rapidly, resulting in

*e-mail:bnunercita@163.com a large amount of livestock manure. Previous studies have demonstrated that the livestock manure in China was 3.264 billion tons, which was 1.6 times the total amount of industrial solid waste in 2009 [1-3]. Fischer et al. [4] forecasted China's livestock manure in 2020 will increase by $37 \%$ compared to China's livestock manure in 2007. Obviously, a large number of livestock manure 
would pose a great threat to the environment at present and in the future. In order to solve the problem of environmental pollution caused by LPB, characterizing the potential environmental pollution risk of LPB scientifically was the critical first step.

A series of research has focused on the potential environmental pollution risk of LPB [5-6]. At present, the research mostly adopted methods such as LD, AVPMELFN, PMELFP, and so on. Using the LD, Tamminga [7] found that the LD in Holland and Belgium was 3.29 AU/ha and $3.18 \mathrm{AU} / \mathrm{ha}$ in 2000, while the average LD in EU was only $0.91 \mathrm{AU} / \mathrm{ha}$. Li et al. [8] analyzed the spatial distribution of the LD and calculated the LD in three northeastern provinces. The results showed that the LD in Liaoning Province, Jilin Province, and Heilongjiang Province was 1.64 AU/ha, $1.91 \mathrm{AU} / \mathrm{ha}$, and $0.73 \mathrm{AU} / \mathrm{ha}$, respectively, in 2005. In addition, the LD was often used as a standard for the prevention of potential environmental pollution risks of LPB. For example, the LD in the EU cannot exceed 2 AU/ha [9]. Moreover, Song et al. [10] evaluated potential environmental pollution risks of LPB of Anhui Province by the livestock manure nitrogen load of farmland (LMNLF) and livestock manure phosphorus load of farmland (LMPLF). Liu et al. [11] calculated the total livestock manure of China and evaluated environmental pollution risks by the PMELFN while other researchers carried out related research on potential environmental pollution risks of LPB by the alarm value of the pig manure equivalent load of farmland (AVPMELF) [12-14].

In summary, the existing research was to use different methods to characterize the potential environmental pollution risk of LPB in different scales and regions. However, the different methods for characterizing the potential environmental pollution risk of LPB were different from each other because of different indicators, which made differences in results.

At present, there is still a lack of standard characterization methods of potential environmental pollution risk of LPB and comparative analysis research of different characterization methods of potential environmental pollution risk of LPB in the same area or on the same scale. Therefore, it was difficult to make clear which characterization methods of potential environmental pollution risk of LPB were relatively scientific and reasonable.

The objectives of this study were 1) to characterize the potential environmental pollution risk of LPB in Guangdong counties in seven characterization methods; 2) to display characterization results of different characterization methods of potential environmental pollution risk of LPB visually using geographic information system technology; and 3) to comparatively analyze seven characterization methods of potential environmental pollution risk of LPB with each other by combining with GIS spatial analysis method.

\section{Material and Methods}

\section{Data Sources and Processing}

In order to carry out this research, the basic data should be gained and processed as follows. Firstly, the statistics data of livestock and poultry and farmland in Guangdong counties were gained from the Rural Statistical Yearbook of Guangdong in 2014. The livestock species included cow, beef cattle, draft cattle, pig, sheep, chicken, duck, goose, and rabbit. Secondly, parameters

Table 1. Excretion coefficients and nutrient content of livestock manure and equivalent conversion coefficient in different livestock.

\begin{tabular}{|c|c|c|c|c|c|c|c|c|}
\hline $\begin{array}{c}\text { Livestock } \\
\text { type }\end{array}$ & $\begin{array}{c}\text { Livestock } \\
\text { unit }\end{array}$ & $\begin{array}{c}\text { Manure and } \\
\text { urine type }\end{array}$ & $\begin{array}{c}\text { Feeding } \\
\text { cycle/d }\end{array}$ & $\begin{array}{c}\text { Excretion } \\
\text { coefficients/ } \\
(\mathrm{kg} / \mathrm{d})\end{array}$ & $\begin{array}{c}\text { Nitrogen } \\
\text { content/ } \\
(\mathrm{g} / \mathrm{d})\end{array}$ & $\begin{array}{c}\text { Phosphorus } \\
\text { content/ } \\
(\mathrm{g} / \mathrm{d})\end{array}$ & $\begin{array}{c}\text { Pig } \\
\text { equivalent } \\
\text { manure (N) }\end{array}$ & $\begin{array}{c}\text { Pig } \\
\text { equivalent } \\
\text { manure }(\mathrm{P})\end{array}$ \\
\hline Pig & 9.09 & Manure & 199 & 2.00 & 5.88 & 3.41 & 1 & 1 \\
\hline Draft cattle & 1 & Manure & 365 & 20.00 & 4.37 & 1.18 & 0.74 & 0.35 \\
\hline Beef cattle & 1.14 & Manure & 365 & 20.00 & 4.37 & 1.18 & 0.74 & 0.35 \\
\hline Cow & 0.74 & Manure & 365 & 25.00 & 4.37 & 1.18 & 0.74 & 0.35 \\
\hline Sheep & 6.98 & Manure & 365 & 2.60 & 7.50 & 2.60 & 1.28 & 0.76 \\
\hline Chicken & 250 & Manure & 210 & 0.12 & 9.84 & 5.37 & 1.67 & 1.57 \\
\hline Duck & 250 & Manure & 210 & 0.13 & 11.00 & 6.20 & 1.87 & 1.82 \\
\hline Rabbits & 151.30 & Manure & 90 & 0.16 & 7.73 & 1.60 & 1.31 & 0.47 \\
\hline Pig & 9.09 & Urine & 199 & 3.30 & 3.30 & 0.52 & 0.56 & 0.15 \\
\hline Draft cattle & 1 & Urine & 365 & 10.00 & 8.00 & 0.40 & 1.36 & 0.12 \\
\hline Cow & 0.74 & Urine & 365 & 13.00 & 8.00 & 0.40 & 1.36 & 0.12 \\
\hline Beef cattle & 1.14 & Urine & 365 & 10.00 & 8.00 & 0.40 & 1.36 & 0.12 \\
\hline
\end{tabular}


such as feeding cycle, excretion coefficient of livestock, and the nutrient content coefficient of livestock manure were gained by references (Table 1) [8, 14-17]. Thirdly, the digital distribution map of in Guangdong counties was digitized according to the administrative map of Guangdong of 1:100 000 using ArcGIS9.3 software. Furthermore, ArcGIS9.3 software was used to realize the correlation between the digital distribution map of Guangdong counties and the statistics data of livestock and poultry and farmland.

Feeding cycle, excretion coefficients, nitrogen content, and phosphorus content derived from [8, 14, and 16]; livestock unit derived from [15] and [17]; pig equivalent manure $(\mathrm{N})$ and pig equivalent manure $(\mathrm{P})$ is calculated according to nitrogen content and phosphorus content.

\section{Calculation Method of Livestock Density}

LD was the amount of livestock units per unit farmland area, which was often used as one of the indicators to measure agricultural loss risk of nitrogen and phosphorus [8]. Due to the difference of excretion coefficient of livestock and nutrient content coefficient of livestock manure. Therefore, to facilitate LD calculation, the amount of livestock was converted into the international standard livestock unit. The LD was calculated as follows $[8,17]$ :

$$
M=W_{\text {num }} / S
$$

...where $\mathrm{M}$ is the $\mathrm{LD}, \mathrm{AU} / \mathrm{ha} ; \mathrm{W}_{\text {num }}$ is the amount of livestock unit, $\mathrm{AU}$; and $\mathrm{S}$ is farmland area, ha.

\section{Calculation Method of Livestock Manure Nutrient Load of Farmland}

At present, the main way livestock manure was treated was as organic fertilizer to farmland. Therefore, farmland was taken as the actual load area for calculating the livestock manure phosphorus load. The livestock manure nutrient load of farmland (LMNLF) was calculated as follows $[5,18]$ :

$$
F_{\text {farmland }}=\sum_{i=1}^{m}\left(N u m_{i} \times D_{i} \times f_{i} \times N u \text { tri }_{i} / S\right)
$$

...where $\mathrm{F}_{\text {farmland }}$ is the LMNLF, $\mathrm{kg} / \mathrm{ha} ; \mathrm{Num}_{\mathrm{i}}$ is the amount of livestock; $D_{i}$ is the feeding period, $d ; f_{i}$ is excretion coefficient of livestock, $\mathrm{kg} / \mathrm{d}$; Nutri is nutrient content coefficient of livestock manure, $\mathrm{g} / \mathrm{kg} ; \mathrm{m}$ is number of livestock manures source; and $\mathrm{S}$ is farmland area, ha.

Calculation Method of Pig Manure Equivalent Load of Farmland and the Alarm Value of Pig Manure Equivalent Load of Farmland

Due to fertilizer efficiency, differences of livestock manure between different types of livestock manure vary greatly, so the different types of livestock manure were often converted into the pig equivalent manure. And the PMELF and AVPMELF were used to characterize potential environmental pollution risk of LPB. It was calculated as follows [19]:

$$
\begin{aligned}
& Z=Y_{\text {nит }} / S \\
& R=Z / Z_{\text {max }}
\end{aligned}
$$

...where $\mathrm{Z}$ is the PMELF, $\mathrm{kg} / \mathrm{ha} ; \mathrm{Y}_{\text {num }}$ is the amount of pig manure equivalent; $\mathrm{S}$ is farmland area, ha; $\mathrm{R}$ is the AVPMELF; and $Z_{\max }$ is the maximum suitable application amount of organic fertilizer taking pig manure equivalent as standard, $\mathrm{kg} / \mathrm{ha}$.

\section{Results and Discussion}

We determined the grading standards of different characterization methods of potential environmental pollution risk of LPB from the relevant literature (Table 2) [8, 10, 19-21].

On this basis, seven characterization methods were used to characterize potential environmental

Table 2. Grading standard of seven characterization methods of potential environmental pollution risk of LPB.

\begin{tabular}{|c|c|c|c|c|c|c|}
\hline $\begin{array}{c}\text { Characterization methods of potential environmental } \\
\text { pollution risk of LPB }\end{array}$ & \multicolumn{5}{|c|}{ Grading standards } \\
\hline LD (AU/ha) & $<1$ & $1-1.5$ & $1.5-2$ & $2-2.5$ & $2.5-3$ & $>3$ \\
\hline LMNLF (kg/ha) & $<90$ & $90-110$ & $110-130$ & $130-150$ & $150-170$ & $>170$ \\
\hline LMPLF (kg/ha) & $<20$ & $20-25$ & $25-30$ & $30-35$ & $30-40$ & $>40$ \\
\hline PMELFN (t/ha) & $<10$ & $10-15$ & $15-20$ & $20-25$ & $25-30$ & $>30$ \\
\hline PMELFP (t/ha) & $<10$ & $10-15$ & $15-20$ & $20-25$ & $25-30$ & $>30$ \\
\hline AVPMELFN & $<0.4$ & $0.4-0.7$ & $0.7-1.0$ & $1.0-1.5$ & $1.5-2.5$ & $>2.5$ \\
\hline AVPMELFP & $<0.4$ & $0.4-0.7$ & $0.7-1.0$ & $1.0-1.5$ & $1.5-2.5$ & $>2.5$ \\
\hline
\end{tabular}


pollution risk of LPB in Guangdong counties in 2013 (Fig. 1).

The results showed that potential environmental pollution risk of LPB in Guangdong counties of different characterization methods were generally uneven in spatial distribution. In general, the potential environmental pollution risk of LPB in counties of Guangdong had gradually increased from the northeast to the southwest. In view of the spatial distribution scope of counties exceeding the safety thresholds of potential environmental pollution risk of LPB, the largest, second largest, and least largest characterization methods was the alarm value of the PMELFN, LD, and PMELFP. Comparing and analyzing the seven characterization method results, the spatial distribution scope of counties exceeding the safety thresholds by the LMPLF included the spatial distribution scope of counties exceeding the safety thresholds by the LMNLF, while the spatial distribution scope of counties exceeding the safety thresholds by the PMELFN was more than the PMELFP.

According to statistical results, the number of counties exceeding the safety thresholds had large differences among different characterization methods. The maximum number of counties exceeding safety thresholds was 74 , accounting for $82.22 \%$ of the total number of counties in the AVPMELFN. Among them, the maximum and minimum values of potential environmental pollution risk of LPB were 6.43 in Shunde Ditrict and 0.23 in Longmen County. The second number of counties exceeding safety thresholds was 53 , accounting for $53.89 \%$ of the total number of counties in the LD. Among them, the maximum and minimum values of potential environmental pollution risk of LPB was 22.60 AU/ha in the Shunde Ditrict and 0.79 AU/ha in Longmen County. The minimum number of counties exceeding safety thresholds was 10 , accounting for $11.11 \%$ of the total number of counties in the pig manure equivalent load of farmland calculated by phosphorus (AVPMELFP). Among them, the maximum and minimum values were $151.80 \mathrm{t} / \mathrm{ha}$ in Shunde District and $3.87 \mathrm{t} / \mathrm{ha}$ in Longmen County. The LMPLF was consistent with the AVPMELFP in a number of counties exceeding safety thresholds, and the maximum and minimum values of potential environmental pollution risk of LPB.

The maximum value of potential environmental pollution risk of LPB was in Shunde District in all seven characterization methods. The minimum value of potential environmental pollution risk of LPB of the LMPLF, PMELFP, and PMELFP was in Shixing County. The minimum value of potential environmental pollution risk of LPB of the other four characterization methods was in Longmen County. Moreover, ten counties (including Sanshui, Xinyi, Nanxi, and Shunde Ditrict) were all exceeding safety thresholds of potential environmental pollution risk of LPB in seven characterization methods.

To avoid the environmental pollution risk of LPB in these ten counties, the solutions should be prepared, such as reducing the amount of livestock and poultry, increasing farmland area, transporting excess livestock manure to other counties not exceeding safety thresholds of potential environmental pollution risk of LPB, transforming livestock manure into biogas, and so on. Which solution would be adopted depends on the actual situation of each county.

The results demonstrated that there is a great difference in spatial distribution scope and the number of counties exceeding the safety thresholds of potential environmental pollution risk of LPB in seven characterization methods. The reason was that different characterization methods adopted different indicators that have the stress. Results of studies conducted by [10] and [20] also found that the results obtained by characterization methods of LMNLF and LMPLF were distinctly different. The results in this paper were essentially consistent with the research conducted by [21] in that there existed significant discrepancies among characterization methods of LD, LMNLF, and LMPLF.

The results also showed that the number of counties exceeding the safety thresholds had large differences among different characterization methods. And the alarm value of the PMELFN had the maximum

Table 3. Statistical results of different characterization methods of potential environmental pollution risk of LPB.

\begin{tabular}{|c|c|c|c|c|c|}
\hline $\begin{array}{c}\text { Characterization methods of potential } \\
\text { environmental pollution risk of LPB }\end{array}$ & $\begin{array}{c}\text { Safety } \\
\text { thresholds }\end{array}$ & $\begin{array}{c}\text { Ratio of exceeding } \\
\text { safety threshold }\end{array}$ & $\begin{array}{c}\text { Maximum } \\
\text { value }\end{array}$ & $\begin{array}{c}\text { Minimum } \\
\text { value }\end{array}$ & $\begin{array}{c}\text { Average } \\
\text { value }\end{array}$ \\
\hline LD (AU/ha) & 2 & $53.89 \%$ & 22.60 & 0.79 & 3.33 \\
\hline LMNLF (kg/ha) & 170 & $20.00 \%$ & 1129.54 & 163.78 & 38.54 \\
\hline LMPLF (kg/ha) & 40 & $48.89 \%$ & 516.88 & 13.14 & 52.81 \\
\hline PMELFN (t/ha) & 30 & $23.33 \%$ & 192.75 & 7.01 & 27.42 \\
\hline PMELFP (t/ha) & 30 & $11.11 \%$ & 151.80 & 3.87 & 17.10 \\
\hline AVPMELFN & 0.4 & $82.22 \%$ & 6.43 & 0.23 & 0.98 \\
\hline AVPMELFP & 0.4 & $50.00 \%$ & 5.06 & 0.13 & 0.52 \\
\hline
\end{tabular}

Safety threshold of LD derived from [17]; safety threshold of LMNLF derived from [10]; safety threshold of LMPLF derived from [21]; PMELFN and PMELFP derived from [16]; AVPMELFN and AVPMELFP derived from [19] 
a).Livestock manure nitrogen load of farmland

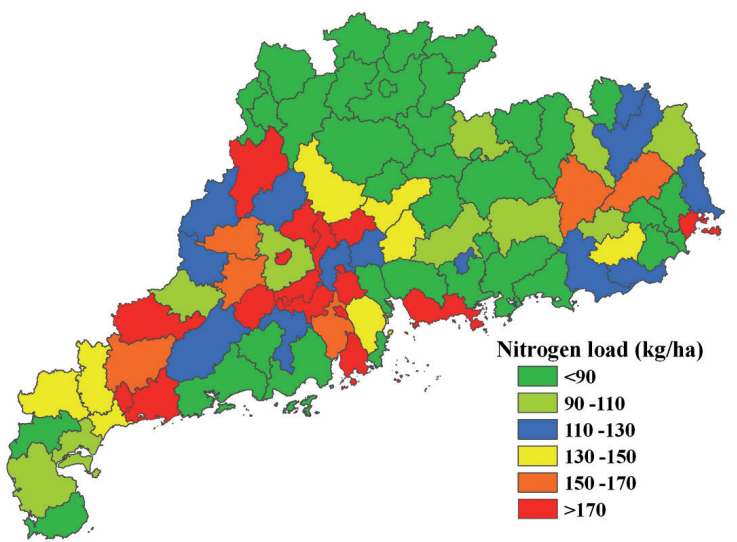

c) The alarm value of pig manure equivalent load of farmland (N)

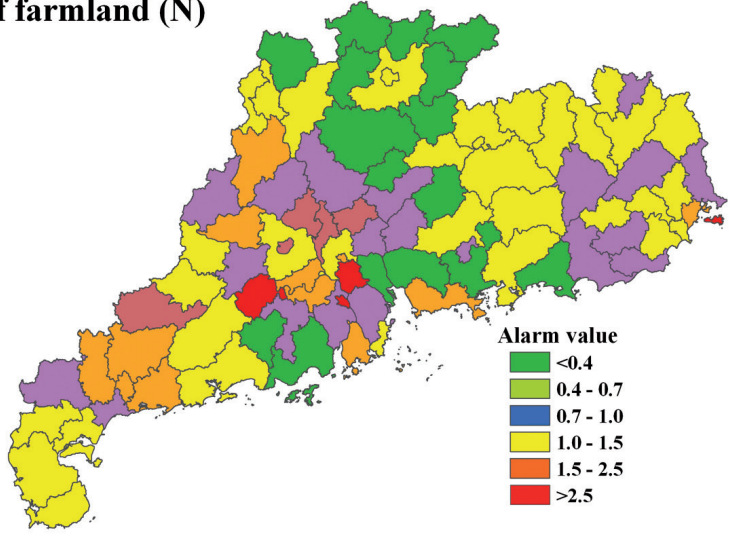

e) Pig manure equivalent load of farmland (N)

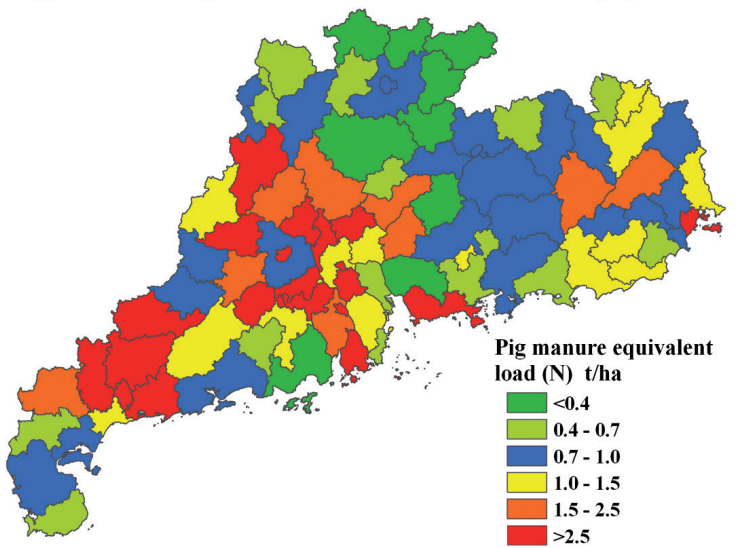

g) Livestock density

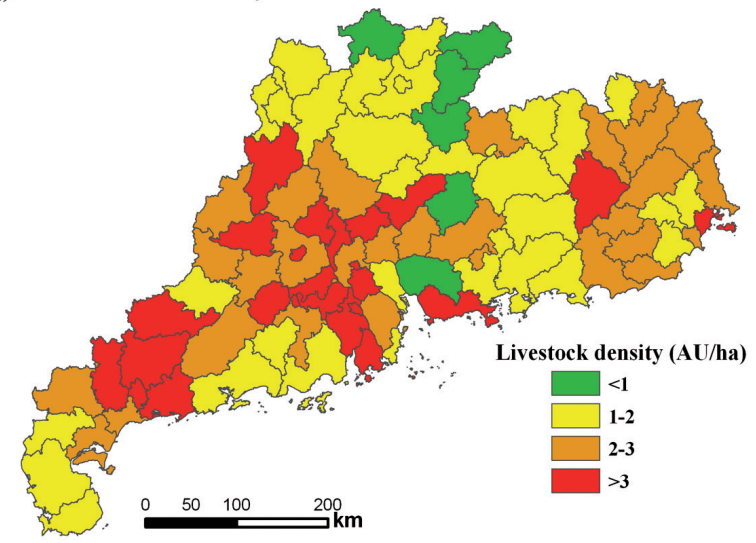

b) Livestock manure phosphorus load of farmland

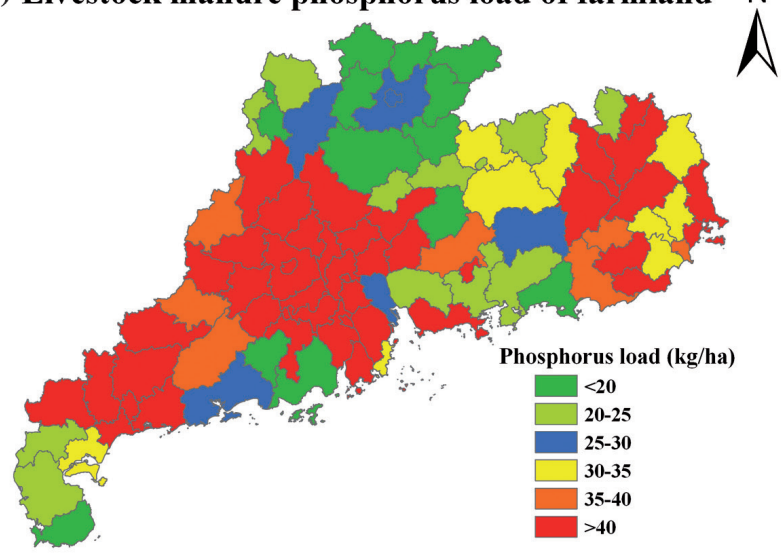

d) The alarm value of pig manure equivalent load of farmland (P)

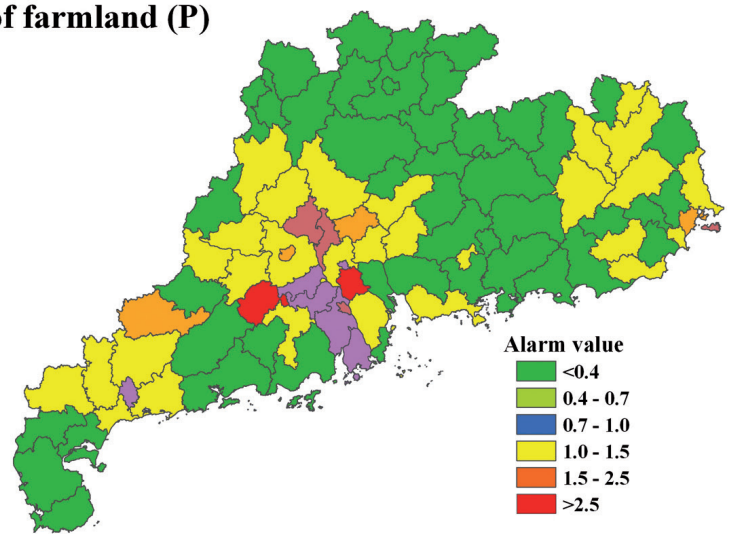

f) Pig manure equivalent load of farmland (P)

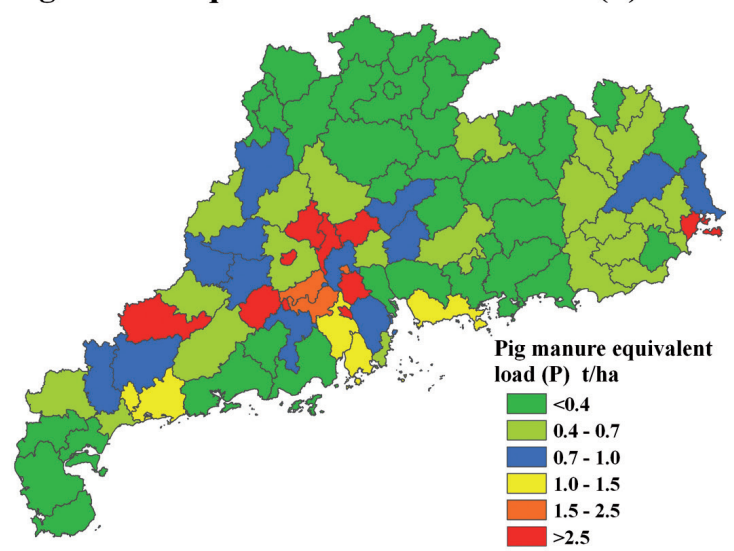

h) Counties exceed the safety threshold of seven characterization methods

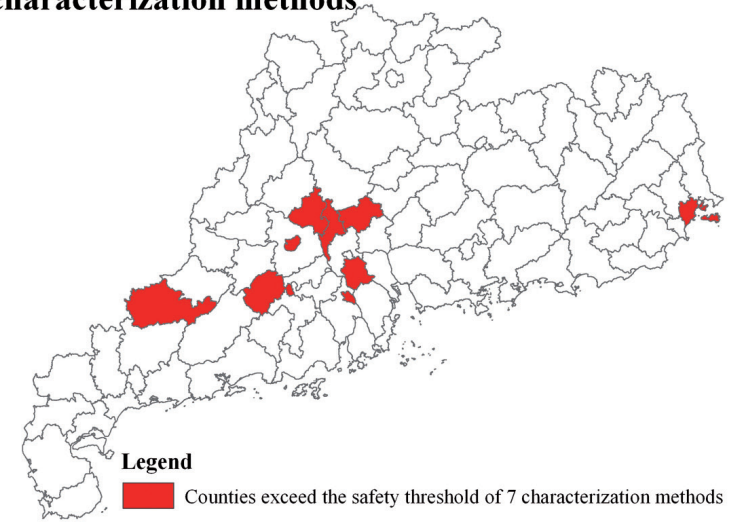

Fig. 1. Spatial distribution results of seven characterization methods of potential environmental pollution risk of LPB in Guangdong counties. 
number of counties exceeding safety thresholds, while the PMELFP had a minimum number of counties exceeding safety thresholds. The Shunde District was the most serious potential environmental pollution risk of LPB in all seven characterization methods. The main reason was that the total farmland area of the Shunde District was only 1223.94 ha, which was the third least in Guangdong, only just more than 264.54 ha in Fushan city and 450.41 ha in Nanxi County. In all seven characterization methods, the stringent method was the alarm value of the PMELFN followed by LD, and the least stringent method was the PMELFP.

Compared to the results of potential environmental pollution risk of LPB characterized by one or two characterization methods in Li et al. [8], Song et al. [10], Huang et al. [12] and Zhu et al. [14], these results used seven characterization methods to characterize potential environmental pollution risk of LPB and comparatively analyzed seven characterization methods of potential environmental pollution risk of LPB with each other.

This result was basically consistent with the results conducted by Chen et al. [22] that the highest risk alert level was found in Pearl River Delta areas,particularly in the Xijiang River basin area.

Through the analysis of the existing literature, the alarm value of the PMELFN had often been used to characterize potential environmental pollution risk of LPB $[19,23]$. The LD was generally used as standard to make regulations by European and American [2425]. Our research further confirmed above research or laws, and regulations had a good scientific rationality. Therefore, in view of the sustainable development of LPB, characterization methods of potential environmental pollution risk of LPB should prefer to select the alarm value of the PMELFN and LD. And we should try to avoid selecting PMELFP, LMNLF, and PMELFN. In view of the fact that there was no unified characterization method to characterize the potential pollution of LPB in China, we suggest that the Ministry of Agriculture and Ministry of Environmental Protection take the alarm value of the PMELFN and LD as a risk assessment index to characterize the potential environmental pollution risk of LPB.

\section{Conclusions}

This study was conducted to characterize potential environmental pollution risk of LPB in counties of Guangdong Province by using seven characterization methods. And seven characterization methods were comparatively analyzed with each other. How to select suitable characterization methods of potential environmental pollution risk of LPB are the key objectives for future research. Different characterization methods of potential environmental pollution risk from livestock and poultry breeding need to be comparatively analyzed in a wider range. In our study, we have only emphasized characterization methods of potential environmental pollution risk of LPB in county scale and single year. In the future, more work should be done to characterize potential environmental pollution risk of LPB and comparatively analyze different characterization methods of potential environmental pollution risk of LPB in different years and different scales such as city scale, town scale, village scale, and so on.

\section{Acknowledgements}

This research had been partly supported by the National Natural Science Foundation of China under Grant No. 41601601, 61501249, the Natural Science Foundation of Fujian under Grant No.2016J01713, the Natural Science Foundation (NSF) of Jiangsu Province for Youth under Grant No.BK20150855, and the Project funded by China Postdoctoral Science Foundation under Grant No.2018M632348.

\section{Conflict of Interest}

The authors declare no conflict of interest.

\section{References}

1. China animal husbandry Yearbook Editorial Committee. China animal husbandry Yearbook, Beijing: China Agriculture Press, 2000.

2. ZHANG T., BU M.D., GENG W. Pollution status and biogas-producing potential of livestock and poultry excrements in China. Chinese Journal of Ecology, 31, 1241, 2012.

3. QIU H.G., LIAO S.P., JING Y., LUAN J. Regional differences and development tendency of livestock manure pollution in china, Environmental Science, 34 (7), 2766, 2013.

4. FISCHER G., ERMOLIEVA T., ERMOLIEV Y., VAN VELTHUIZEN H. Livestock production planning under environmental risks and uncertainties. Journal of Systems Science and Systems Engineering, 15 (4), 399, 2006.

5. SONG D.P., ZHUANG D.F., CHEN W. Risk assessment of the farmland and water contamination with the livestock manure in anhui province. Environmental Science, 35 (1), 110, 2012.

6. CHADWICK D., JIA W., TONG Y., YU G., SHEN Q., CHEN Q. Improving manure nutrient management towards sustainable agricultural intensification in China. Agriculture Ecosystems \& Environment, 209, 34, 2015.

7. TAMMINGA S. Pollution due to nutrient losses and its control in European animal production. Livestock Production Science, 84 (2), 101, 2003.

8. LI W., LI Y.X., ZHANG F.S., LIN C.Y., XIONG X., ZHONG Z. The spatial and temporal distribution features of animal production in three northeast provinces and the impacts of manure nutrients on the local environment. Journal of Agro-Environment Science, 26 (6), 2350, 2007 
9. YAN B. Moderate scale and potential scale estimation of livestock and poultry breeding in county scale based on multiple limited standards: a case study of Anhui Province. Environmental Pollution \& Control, 39 (5), 467, 2017.

10. SONG D.P., ZHUANG D.F., CHEN W. Risk assessment of the farmland and water contamination with the livestock manure in Anhui province. Environmental Science, 33 (1), 110, 2012.

11. LIU Z., DUAN Z.Q. Distribution of manure resources and environmental loads of agro-ecological regions in China. Resources Science, 32 (5), 946, 2010.

12. HUANG M.L., XIA Y., FAN X. P., HUANG M., WU M.Q., LIU D.B., ZHANG F.L. Pollution status and total amount control of livestock and poultry breeding in Hubei province. Resources \& Environment in the Yangtze Basin, 26 (2), 209, 2017.

13. ZHANG X.H., WANG F., ZHEN X.S., XIAN X.U., SHEN J.Y. Temporal and spatial distributions and pollution prevention of livestock mannure in Sichuan. Resources \& Environment in the Yangtze Basin, 27 (2), 433, 2018.

14. ZHU J.C., ZHANG Z.Q., FAN Z.M., LI R.H. Biogas potential, cropland load and total amount control of animal manure in China. Journal of Agro-Environment Science, 33 (3), 435, 2014.

15. WANG X.L., WU C.Q., FENG A.P., MA Y.H., WANG X.X., CHEN M.P. Application of DPeRS model on estimation of non-point source pollution load of ammonia nitrogen and chemical oxygen demand in Chao Lake basin. Acta Scientiae Circumstantiae, 35 (9), 2883, 2015.

16. GENG W., HU L., CUI J.Y., BU M.D., ZHANG B.B. Biogas energy potential for livestock manure and gross control of animal feeding in region level of China. Transactions of the Chinese Society of Agricultural Engineering, 29 (1), 171, 2013.

17. MENG C., LI Y.Y., XU X.G., GAO R., WANG Y., ZHANG M.Y., WU J.H. A case study on non-point source pollution and environmental carrying capacity of animal raising industry in subtropical watershed. Acta Scientiae Circumstantiae, 33 (2), 635, 2013.

18. YAN B.J., QIAN Y.G., PAN Y.C. A method to estimate livestock manure nutrient load of farmland in field patch scale. Fresenius Environmental Bulletin, 25 (6), 1942, 2016.

19. LAN Y., LIU S. J., XIANG P.A. Quantifying the pollution loading from livestock and poultry of family farm-based on the sample of counties in Hunan province. Economic Geography, 35 (10), 187, 2015.

20. WU L.F., OUYANG Z., XIE X.L. Nitrogen and phosphorus balance of cropland at regional scale for integrated croplivestock farming system in two different areas. Journal of Natural Resources, 26 (6), 943, 2011.

21. FENG A.P., WANG X.L., LIU Z., WANG X.X. Temporalspatial analysis of environmental risks from animal production in Northeast China. Research of Environmental Sciences, 28 (6), 967, 2015.

22. CHEN K.L., LI J.T. ZHONG X.L., WANG F., NI J., LI X.J. Analysis on Spatial-temporal Variation Characteristics and Farmland Load of Poultry and Livestock Excrement in Guangdong Province. Journal of Anhui Agricultural Sciences, 40 (12), 7177, 7185, 2012.

23. YAO W.J., ZHAO L.G. Research on the dynamic coupling of environmental load with economy growth in the industry of livestock and poultry breeding: Based on the time-series data of Zhejiang in 1978-2012. Journal of China Agricultural University, 19 (6), 242, 2014.

24. MUBAREKA S., MAES J., LAVALLE C., ROO A.D. Estimation of water requirements by livestock in Europe. Ecosystem Services, 4, 139, 2013.

25. YAN B., SHI W., WANG Z., ZHU M., LIU Y. The environmental risk assessment in farmland polluted by livestock and poultry feces in Fujian province based on multi-indices. Acta Scientiae Circumstantiae, 37 (3), 1146, 2017. 
